\section{Bolivia: estrategias viales hacia un "país de contactos"}

\section{Q Bianca De Marchi Moyano}

Centro de Investigaciones Sociales de la Vicepresidencia, Bolivia

\author{
Huascar Ignacio Morales Quintela \\ Centro de Investigaciones Sociales de la Vicepresidencia, Bolivia
}

\author{
María Cristina Machicado Murillo \\ Centro de Investigaciones Sociales de la Vicepresidencia, Bolivia
}

Recibido: 13 de septiembre de 2017. Aceptado: 13 de diciembre de 2017.

\section{Resumen}

El artículo presenta algunos avances de investigación sobre el desarrollo vial (férreo y carretero) de Bolivia, a partir de su relación con el discurso del "país de los contactos". Se ofrece una descripción general -desde una mirada histórica y geográfica- de los intentos del Estado boliviano para conectarse a los países vecinos, consolidar sus fronteras y activar efectivamente una estrategia de implantación de vías de transporte férreo y carretero que tengan la capacidad de unir, a través de Bolivia, las costas del Pacífico y del Atlántico. Se ponen en evidencia algunas de las dificultades y los desafíos en el establecimiento de vías de transporte para alcanzar las fronteras y las consecuencias de aquello en la estructuración del territorio y el sistema de centros poblados. En ese marco, se discute la construcción discursiva del Estado boliviano entorno a los proyectos actuales de transporte e integración, tal es el caso del Corredor Ferroviario Bioceánico Central (CFBC) y la adecuación de las carreteras del eje central en diseño de doble vía. El discurso del "país de los contactos" encuentra -posiblemente por primera vez en la historia boliviana- las condiciones materiales suficientes para convertirse en una realidad. Sin embargo, no parece evitar tensiones entre las escalas locales de movilidad y los proyectos territoriales que representan ambos medios y vías de transporte.
Palabras clave

Bolivia Corredor Integración Territorio Transporte

Palabras-chave

Bolívia Corredor Integração Território Transporte 


\section{Bolivia: road strategies towards a "country of contacts"}

\begin{abstract}
This article presents partial findings from a research project regarding road and railroad development in Bolivia, based on its relation with the discourse around "the country of contacts". It offers a general description -from a historical and geographical perspective- of the attempts by the Bolivian state to become connected to neighboring countries, consolidate its borders, and activate a strategy of road and railroad development which are able to link the Pacific and Atlantic coasts by passing through Bolivia. Evidence is put forth in relation to some of the difficulties and challenges in establishing transport routes to reach these borders, resulting in consequences for the structure of the territory and the human settlement system. Within this framework, we discuss the discursive construction of the Bolivian state with regards to current transport and integration projects such as the Central Bioceanic Rail Corridor (CFBC) and the upgrading of central axis highway towards a motorway. The discourse of "the country of contacts" finds - possibly for the first time in Bolivian history-adequate conditions to become a reality. However, it fails to avoid tensions with local-level mobility systems, or territorial projects which represent both forms and routes of transport.
\end{abstract}

\section{Introducción}

A lo largo de la historia boliviana es recurrente el discurso sobre las dificultades de integración de su territorio, ya sea hacia sus regiones internas, a los países vecinos o, en especial, a las costas del Atlántico y del Pacífico (Blanes et al., 2003:140; Dalence, 2013:227; Cuadros, 1996; Mendoza, 1925). Este artículo analiza esa problemática, a partir de la historia ferroviaria y carretera-automovilística del país y de su relación con la construcción de la narrativa del "país de los contactos", desde fines del siglo XIX hasta la actualidad plurinacional. Se trata de un avance de investigación en el que sostenemos que las vías de transporte y los cambios de las rutas prioritarias en el país dejan huellas espaciales y que éstas son una aproximación válida para estudiar la composición y la integración del territorio en la historia: pueden ser leídas como un palimpsesto (Corboz, 2001). Además, la lectura espacial se sustenta en afirmaciones como la de Raymond Crist (1944) quien sugiere que el transporte fácil y barato es la fuerza cohesiva para unir un país, más aún si se toma en cuenta la lógica "modernizadora" (Navas, 2013) que se vincula a la noción contemporánea de vialidad, a escala nacional e internacional.

Al nacer Bolivia a la vida republicana, mantiene la inercia de los vínculos y flujos del sistema colonial (Cuadros, 1996:135). Cabe recordar que a fines del siglo XVIII el sistema ya sufre un importante deterioro, principalmente por el declive de su motor minero en Potosí (Blanes et al., 2003:83). Esa inercia define una integración difícil y problemática ya que los puntos y rutas de conexión, que juegan un rol capital para dinamizar el territorio, son poco estimulados. Los centros poblados de la República de Bolivia se encuentran en el centro del continente y lejos de los puertos; el largo y difícil viaje por los caminos de herradura coloniales poco mantenidos limita la voluntad del Estado de aprovechar el amplio espacio que se pretende controlar (Dalence, 2013:227). Así se profundiza el aislamiento de sus nodos y sus dificultades de comunicación interna y externa. La ubicación continental de las principales ciudades bolivianas tiene sentido y relevancia en un sistema amplio y hegemónico como el colonial, articulado principalmente a Potosí y luego -en ultramar- al impero Español (López, 2016:24-26), pero en el nuevo contexto de Estados nacionales debe encontrar una renovada significación, conectividad y practicidad.
Keywords

Bolivia Corridor Integration Territory Transport 
Así, durante el siglo XIX, la consolidación del territorio es lenta; pese a los esfuerzos constantes pero poco fructuosos de producir accesibilidad e integración. Al respecto es significativo recuperar lo descrito por Marsh a principios del siglo XX:

¡Faltan caminos! ¡Faltan Ferrocarriles! no es otro el grito que persiste en la política boliviana. La necesidad de ferrocarriles es doble: políticamente, para unir los departamentos orientales separados por la cordillera real del centro vital de la República, a la meseta y valles contiguos de la altiplanicie; y económicamente, para hacer accesible la riqueza, no sólo al mundo en general, sino a su propio país, en forma que el este y el oeste puedan complementarse como la naturaleza ha determinado, aunque ha impedido también (1928:97).

Las dificultades de vincular las ciudades principales de Bolivia (Sucre, Potosí, Cochabamba y en menor medida La Paz) hacia las fronteras se ven reflejadas en las campañas militares de la guerra del Pacífico (1879) y del Acre (1899-1903). El lento desplazamiento de tropas para una defensa militar efectiva ilustra la complejidad de la movilidad y del transporte en la Bolivia de fines del siglo XIX y coadyuvan a la instalación de lo que Perrier-Bruslé considera "los dos principales males geográficos de Bolivia: las pérdidas territoriales y el enclaustramiento" (2015:104).

Jaime Mendoza, para inicios del siglo XX, ilustra la ambivalente posición boliviana al momento de abordar el desafío de la articulación hasta las fronteras internacionales. Afirma que existe "Cierto peligro de sentir con más facilidad la atracción de los países limítrofes, el macizo boliviano aún no ha podido establecer vínculos sólidos y firmes con esos territorios" (1925:53). Efectivamente, el autor hace referencia al vasto espacio oriental de tierras bajas boliviano, que sentiría cierta atracción hacia la Argentina o el Brasil (Limpias, 2009:13; Bieber, 2016:121) y que no está vinculado a la parte central del macizo (el altiplano), donde se ubican las ciudades principales del país. Esa sensación de amenaza se relaciona con la debilidad estatal de consolidar las fronteras e integrar efectivamente su territorio, en comparación a lo logrado por los países vecinos (que articulan antes sus espacios limítrofes como lo muestran los años de llegada de las vías férreas de los países vecinos hasta Bolivia en la Figura 1). Pese a ese clima de sospecha, los primeros proyectos de conquista del espacio interno y hacia las fronteras tienen que ver con la explotación de recursos naturales y el establecimiento de las vías más rápidas para su exportación a cualquier océano. En ese marco, se desarrollan estrategias de vinculación binacional en los espacios de frontera, alentadas por la intención exportadora y empresarial.

A casi 100 años de la fundación de Bolivia y a raíz de las pérdidas territoriales, va tomando cuerpo una idea que justifica la existencia misma del Estado-nación en el contexto regional. En efecto, son los demás países los que llegan a vincular sus fronteras con Bolivia antes que el Estado boliviano. Sin embargo, esta situación es repensada como ventajosa por la diplomacia del país en relación directa con el estímulo a la vialidad $^{1}$. Así toma cuerpo la idea de que el país debe comunicarse con los otros Estados sudamericanos y facilitar el flujo regional hacia las costas de ambos océanos a través de su territorio. Esa instalación de la idea del "país de contactos" (Perrier-Bruslé, 2015) está asociada a diferentes condiciones ajenas al Estado boliviano. En primer lugar, el crecimiento económico, poblacional y tecnológico de las economías de Brasil y Argentina es esencial para provocar la concepción de integración subcontinental, pues instala la necesidad del comercio de esos países hacia otros a través de Bolivia. Otro factor influyente es la apertura del canal de Panamá (1914) y la creciente importancia de la costa del Pacífico, principalmente para conectarse con la pujante economía del Oeste norteamericano y, más tarde, con los países asiáticos. Pero en lo que se refiere a la perspectiva boliviana, la condición fundamental es el paso de concebir al país desde una situación poco ventajosa (principalmente: la mediterraneidad) a una donde su ubicación continental puede aprovecharse de forma estratégica.
1. Retomamos la idea de que las "variables fundamentales y estrictamente interrelacionadas de dicho discurso fueron la construcción de una vialidad que permitiera la ocupación de todo el territorio por parte de una población, interna o foránea, que explotaría los recursos naturales y permitiría el progreso económico y social del país al mismo tiempo que salvaguardaría la bolivianidad en todas las fronteras" (García, 2000:57). 
Con esa contextualización, la exposición que proponemos se divide en tres apartados. El primero profundiza el proceso histórico de la conquista del territorio y de control de las fronteras, resaltando la experiencia ferroviaria en el país desde la década de 1870 hasta 1970. El segundo subtítulo trata de recuperar y analizar los intentos contemporáneos (2005-2017) que aprovechan la posición continental boliviana para articular los flujos sudamericanos $^{2}$, donde juegan un papel importante las inversiones proyectadas en carreteras y ferrovías. El tercer apartado brinda pistas sobre el efecto territorial de la instalación de estas obras de vinculación en los asentamientos vinculados al ferrocarril y las carreteras en una parte del eje bioceánico, al occidente del país (cercanías de La Paz y Oruro), hacia los puertos en el Pacífico. Finalmente, al cierre del artículo, se desarrollan algunas ideas centrales sobre las vías de transporte y la integración del territorio boliviano.

\section{La integración boliviana: los vínculos ferroviarios binacionales}

Los esfuerzos por vincular Bolivia con sus vecinos a través del ferrocarril dan cuenta de la necesidad y deseo de los gobernantes de la época por facilitar la exportación de materias primas y la importación de bienes de consumo. Son conocidos los intentos del Estado y de actores privados bolivianos por vincular, por ejemplo, la frontera Norte del país, con Brasil durante los auges de la quina y la goma elástica a finales del siglo XIX y albores del XX, incluso con el costoso intento de articulación ferroviaria para salvar los obstáculos naturales a la navegación (García, 2000:84-85; Guiteras, 2012:8183). Algo similar sucede en el occidente boliviano, en las fronteras con Chile y Perú, para la exportación de minerales (principalmente salitre, plata y estaño); o en el Este y el Sur bolivianos, con Brasil y Argentina, para la exportación de hidrocarburos, ya a principios y mediados del siglo XX.

Nos interesa profundizar el caso de los ferrocarriles, por su relevancia en la concepción modernizadora de los transportes. La construcción de rieles (ver Figura 1) implica un esfuerzo estatal importante, que juega un rol estratégico en la integración binacional impulsada por los gobiernos y apoyada por una estructura de créditos y empréstitos extranjeros. Según Gustavo Rodríguez, esa política ferroviaria -que autoriza la construcción pero concede la ejecución a capitalistas extranjeros- ocasiona una situación "ambigua y contradictoria" (Rodríguez, 2012:36), ya que aumenta la presencia del Estado en el territorio, pero a su vez entrega ese acceso exclusivo a manos extranjeras y facilita el ingreso de importaciones que debilitan las dinámicas productivas locales. Manuel Contreras indica que la vinculación y construcción de rieles está estrechamente relacionada con la supervivencia de los planes políticos, por lo que no sólo son vías económicamente rentables, sino también rutas políticas (Contreras, 2003:282-283).

El primer hito del proyecto ferroviario boliviano se marca en 1884 con la firma del "Pacto de Tregua" con el país vecino Chile que promueve la construcción de una línea para conectar directamente la mina de la Compañía Minera Huanchaca al puerto ya chileno de Antofagasta. Ocho años más tarde, para 1892, el ferrocarril llega desde Antofagasta hasta la ciudad de Oruro con tres locomotoras "Arce", "Oruro" y "Cochabamba" ligando otros centros mineros al comercio internacional. Almaraz señala que la construcción de esta "espina dorsal ferrocarrilera" inicia a su vez una deuda externa de seis y medio millones de boliviano (Almaraz, 1988:67-68). Para 1905 el Estado invita al ingeniero de ferrocarriles norteamericano W. Lee Sisson para implantar -junto a The Bolivian Railway Company- un Plan de Construcciones ferroviarias en Bolivia. El trabajo tiene un costo de 50.000 libras esterlinas y, aunque Sisson elabora una extensa descripción y anexo fotográfico de todo el viaje, el plan nunca se ejecuta. Aun así, el tren se constituye en un símbolo de la modernización y de la impronta liberal de los gobernantes bolivianos de ese periodo.
2. Es posible sugerir que, en las discusiones contemporáneas bolivianas, un discurso vinculado a lo continental y complementario al del país de los contactos es el que propone consolidar a Bolivia como el "corazón energético" de Sudamérica, lo que se refleja en la agenda patriótica impulsada por el gobierno de Morales (Agramont, 2010; Estado Plurinacional de Bolivia, 2014). 


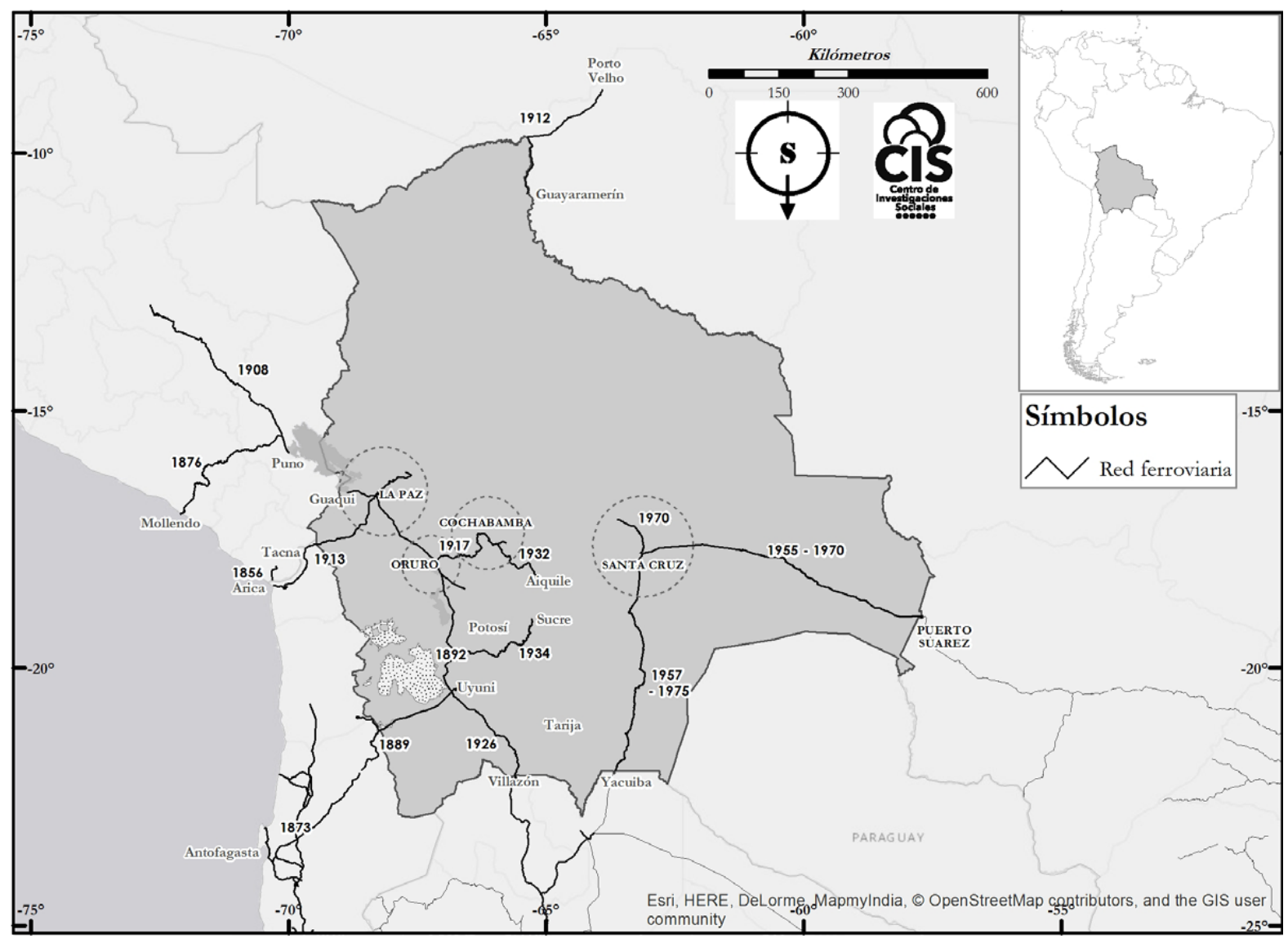

La Figura 1 ilustra el sentido de la construcción de los ferrocarriles en Bolivia. Los rieles fueron tendidos desde las fronteras hacia el interior del país, hecho que está asociado al interés de los países vecinos por ampliar su área de influencia y a las intenciones exportadoras de las élites empresariales y políticas locales. Llama la atención la desconexión de las redes Oriental y Occidental en la parte central, en el llamado "corazón del continente". Es posible afirmar que los tratados binacionales, que fomentan la construcción de ferrovías, son efectivos en base a sus objetivos específicos ligados a la exportación de materias primas. Así, la falta de conexión de la red del Oeste y de la del Este se debe tanto a la poca capacidad de los gobiernos bolivianos para concretar los múltiples intentos de efectivizar esa comunicación, como a la carencia de poder local de empresarios y de los intereses extranjeros por lograr esa conexión.

Adicionalmente, la Figura 1 muestra que no es hasta después de la Guerra del Chaco (1935) que Bolivia extiende las rieles fuera de la red occidental (vinculada principalmente al Pacífico). La ciudad de Santa Cruz se convierte en un punto de conexión ferroviaria en la red oriental, que une a Bolivia con Argentina y Brasil (Limpias, 2009:17). Articula dos principales ramales, uno con destino a Yacuiba-Pocitos y otro a Puerto Suárez-Corumbá. Su gestación, posterior al conflicto con el Paraguay, ya muestra pistas embrionarias de la concepción del "país de contactos" y a su relación con las vías de transporte y recursos naturales.

...Bolivia comenzó a percatarse del poder de negociación internacional que podía otorgarle el control sobre sus reservas de hidrocarburos. Esta percepción no tuvo sus orígenes en las contiendas entre grandes potencias por asegurarse el aprovisionamiento de una u otra materia prima. Fue más bien resultado del interés que empezaron a mostrar Argentina y Brasil por acceder al petróleo del oriente
Figura 1. Mapa de evolución de las vías férreas de la Red Occidental y Oriental en Bolivia. Fuente: Elaboración propia. 
boliviano y a la constelación poco propicia en la que se encontraba el país andino frente al Paraguay cuando, a mediados de 1935, se decretó el cese de hostilidades en el Chaco. La disputa iniciada entre Buenos Aires y Río de Janeiro a partir de 1935/1936 por establecer convenios con el gobierno de La Paz para obtener la materia prima y realizar obras de infraestructura que facilitasen su transporte, hizo surgir en Bolivia la idea de aprovechar aquella pugna para obtener el apoyo argentino y brasileño, tanto en las negociaciones de paz con el Paraguay como para impulsar el desarrollo de su región oriental. Bajo el rótulo "Bolivia tierra de contactos” el país andino comenzó a implementar una política externa de esta naturaleza (Bieber, 2016:121).

En ese marco, la idea de facilitar corredores ferroviarios, a través de tratados con los vecinos, comienza a consolidarse. El primer tramo se realiza a partir de un acuerdo de 1937 y se concreta el año siguiente (Aramayo, 1959:188) ${ }^{3}$. El tren comienza su circulación inaugural en 1957, pero los puentes y otras obras de arte recién se entregan más de 15 años después.

Desde esa perspectiva, el tren Corumbá-Santa Cruz, desarrollado en acuerdo con el Brasil, buscaría contrarrestar esas intenciones de dominio subcontinental argentino. El proyecto de ese ferrocarril hacia la frontera brasileña se realiza sobre la base del Tratado de Petrópolis (1903) (Aramayo, 1959:195). Ya en 1928 se propone cambiar la zona destinada a las construcciones ferroviarias ${ }^{4}$ (inicialmente contemplaba la construcción de rieles que unirían Riberalta-Guayaramerín y San Antonio para salvar las cachuelas del río Madeira). En 1938 se firma el convenio para la construcción entre Puerto Esperanza, Corumbá y la ciudad de Santa Cruz ${ }^{5}$. La entrega oficial del tramo se realiza en 1955, pero -al igual que en la ferrovía hacia Argentina- la finalización de las obras de arte y puentes se da en la década de 1970.

Los trenes orientales marcan la idea de posicionar a Bolivia como un país de interconexiones para los vecinos, un "país de contactos". Sin embargo, como expresa la Figura 1, las redes ferroviarias oriental y occidental están separadas, situación que se mantiene hasta la actualidad a pesar de los múltiples intentos por unirlas. Una de las razones principales de esa desconexión ferroviaria es la integración de la ciudad de Santa Cruz con Cochabamba y el "macizo andino" del país a través de la primera carretera asfaltada de Bolivia en 1954. La construcción de esa carretera es una bisagra histórica en términos de las vías de integración en Bolivia. No sólo es la primera conexión estable entre occidente y oriente, sino que modifica gradualmente la percepción sobre el transporte automotor, promoviendo la dominación de este medio sobre los demás (Cuadros, 1996:164; Blanes et al., 2003:171).

Además, la vía influye en la minimización del antiguo miedo boliviano, citado antes en palabras de Jaime Mendoza, sobre la atracción de Santa Cruz hacia otros países.

En términos culturales relativos, los habitantes de Santa Cruz iniciaron "de la noche a la mañana" tres intensos vínculos interculturales con tres sociedades distintas: la andina, la rioplatense y la brasileña, con las que hasta mediados del siglo XX mantenían relaciones permanentes, pero de baja intensidad, tanto económica como culturalmente. De hecho, las reacciones de los cruceños ante la perspectiva de cambios que se anticipaba vendrían con esas vías de comunicación, demuestra no solo preocupación sino también inseguridad ante lo que enfrentarían (Limpias, 2009:21).

La intención de unir las redes ferroviarias occidental y oriental permanece latente en la segunda mitad del siglo XX. En diferentes momentos, el trazo de construcción de Santa Cruz al río Mamoré se proyecta para favorecer una vinculación a la vía fluvial Ichilo-Mamoré y al mismo tiempo facilitar su contacto con Cochabamba por el Norte chapareño (INC, 1975:s.p; Lema y Alvarado, 1998:153). Uno de los últimos proyectos
3. Para eso, se crea una comisión mixta, argentino-boliviana, cuyo financiamiento es facilitado por el gobierno del país vecino para luego pagarse con hidrocarburos.

4. Con la caída de la extracción gomera el proyecto en esa región pierde fuerza. Paralelamente a esta crisis los precios del mercado favorecen a los recursos hidrocarburíferos dando un nuevo impulso a regiones surorientales del país.

5. El pago del excedente invertido por la parte brasileña inicialmente se propone en hidrocarburos, repitiendo la fórmula del proyecto a Yacuiba. 
que se proponen para fomentar la circulación férrea desde el Estado a través de la Empresa Nacional de Ferrocarriles (ENFE), se desarrolla bajo el auspicio técnico de la Agencia de Cooperación Internacional del Japón (JICA) en 1989.

Sin embargo, el proceso de capitalización de las empresas públicas, que se desarrolla entre 1994 y 1996, afecta directamente a ENFE, lo que impide que cualquier proyección se lleve a cabo, particularmente los intentos por conectar las redes occidental y oriental. En 1995, por los decretos supremos 24185 y 24186, se dispone la capitalización de “... la Empresa Ferroviaria Oriental Sociedad de Economía Mixta (FCO S.A.M.)” y de la "Empresa Ferroviaria Andina Sociedad de Economía Mixta (FCA S.A.M.)" respectivamente. Desde entonces y hasta la actualidad, la Red Oriental de ferrocarriles es gestionada por la empresa Trenes Continentales, bajo el control del grupo estadounidense Genesee \& Wyoming; mientras el sistema occidental queda bajo la responsabilidad de la empresa Cruz Blanca, del grupo chileno Luksic. Para ambos casos, las empresas mantienen por el plazo de 40 años tres tipos de contratos: el de Licencia, el de Concesión y el Contrato de Arrendamiento de Material Rodante (FO, 2012:28; FCA, 2007:35).

La capitalización provoca opiniones diversas. Para 1998 la Asociación Latinoamericana de Ferrocarriles (ALAF), entidad abiertamente favorable a la privatización de los trenes en la región, menciona que la Ferroviaria Oriental: “...transportó 1.102 millones de toneladas, más de $40 \%$ superior que en 1994, el año anterior a su licitación. La productividad laboral había subido a un 248\%" (Thompson, 2006:13). Aunque ese análisis no señala la fuente para ratificar los datos que muestra, los registros accesibles dan cuenta de una relativa estabilidad y rentabilidad en los transportes férreos de ambas empresas desde su adjudicación. En el caso del sistema andino, el movimiento de minerales es central y mantiene el transporte de pasajeros como "responsabilidad social empresarial” o con fines turísticos ${ }^{6}$. Para el caso oriental, la ruta hacia Puerto Quijarro es la de mayor rentabilidad; sus cargamentos más importantes están constituidos por productos agrícolas (sobre todo soya) que se exporta luego por la hidrovía ParanáParaguay ${ }^{7}$. En todo caso, recién en la segunda década del siglo XXI se retoma la idea de los trenes como un proyecto vinculado al país de los contactos a partir del Estado.

\section{Bolivia como actor del flujo transoceánico}

Como se muestra en el anterior acápite, las intenciones de conexión ferroviaria entre el Oriente y Occidente boliviano se mantienen como proyecto truncado durante el siglo XX. Sin embargo, no sólo la capitalización frena el desarrollo ferroviario, sino que el incremento del transporte automotor para comunicar las regiones internas del país desplaza progresivamente al tren como alternativa de transporte y como discurso de modernidad. Algunos autores sugieren que la falta de apoyo estadounidense a los ferrocarriles y su respaldo a los proyectos carreteros es también determinante para su crecimiento en la segunda mitad del siglo XX (Castro, 2013; Villegas, 2013). Aun así, es importante subrayar que en Bolivia se registra un debate en las diferentes entidades estatales que cuestiona la priorización de la articulación carretera o férrea del país.

Efectivamente, la disputa expresada sobre los medios de transporte terrestres, su conexión y en cierta medida duplicidad, se presenta en varios documentos oficiales (JNP, 1961:212; Machicado, [1971] 2015:131). Como muestra el anterior subtítulo, hasta fines del siglo XX, diferentes esfuerzos gubernamentales y proyectos internacionales sostienen su intención de invertir y extender las vías férreas del país, pese a que es una carretera, la de Cochabamba a Santa Cruz, la que logra vincular efectivamente los nodos orientales y occidentales. Así, el propósito de construir una "red" de transporte de múltiples vías y modos integrados logra coordinarse en muy pocos casos hasta la
6. Eso se ratifica con lo que señala la empresa : http:// www.fca.com.bo/busCarril. php (revisión: 10/2016)

7. Tomado de la página web: http://www.fo.com.bo/SERVICIOS/Carga/Exportaciones/ default.aspx (revisión 10/2016) 
actualidad y pronto se impone el tráfico carretero como articulador y en cierta medida subordinador de los demás tipos de transportes. Así, el dominio automotor se asienta como el hegemónico hasta la actualidad. A manera de ejemplo, se sugiere que desde 1955 hasta 1960 el tonelaje de productos movidos en camiones se incrementa 7 veces (Fifer, 1967:5). A eso aporta de forma fundamental la nueva carretera hacia el Oriente: “...faltando aún por concluir el asfalto ya circulaban 500 vehículos por mes y cuando en 1965 estuvo totalmente terminada el tráfico era de 5.000 coches mensualmente" (Castro, 2013:174).

En ese marco, con el desplazamiento del tren como medio de transporte principal, se registra un reemplazo en el discurso del país de contactos. La capacidad boliviana de convertir sus carreteras en corredores interoceánicos registra tanto progresos significativos como también evidentes tropiezos. La idea de desarrollar ejes viales automovilísticos, cuya naturaleza permita facilitar el alcance de las costas (del Pacífico o del Atlántico) se plantea intermitentemente en Bolivia en ese periodo. Una característica distintiva respecto a los intentos ferroviarios, es que las iniciativas dejan de ser de carácter binacional y pasan a ser articuladas por entidades e iniciativas multilaterales (compuestas por financiadores y Estados). Un caso se muestra dentro de los acuerdos en los que participa el país desde 1957 para desarrollar la "Carretera Marginal de la Selva”. Sobre ellos se menciona que:

el 12 de octubre de 1963 a una reunión preliminar en la ciudad de Lima, a los señores Ministros de Obras Públicas de Colombia, Ecuador, Perú y Bolivia, (a la que posteriormente se adhirieron Brasil, Paraguay y Argentina) a objeto de promover un proyecto vial que, bordeando las boscosas estribaciones de la Cordillera de Los Andes, coordinará sus sistemas carreteros en una extensión aproximada de 5.792 kilómetros de longitud por seis metros de ancho. Posteriormente, en sesión de 15 de octubre de 1965, aprobó su recorrido (Pacheco, 1983:14).

En ese contexto se plantean proyecciones, como las señaladas por Machicado en 1971, quien describe la intención de producir varias carreteras entre Cobija y Cachuela Esperanza, así como a Puerto Heath y Rurrenabaque, a fin de facilitar el tránsito desde Lima a Brasilia por el Este de la cordillera de los Andes. Se sostiene que esos trazos deben cumplir con "...objetivos múltiples: acceso a áreas aisladas, incorporación de tierras nuevas, vinculación internacional e integración territorial" (Machicado, [1971] 2015:233). Paralela a esa iniciativa, se promueve otra conocida como carretera Panamericana. El trazo Norte-Sur propone vincular todo el continente Americano desde EUA hasta la tierra del fuego en Argentina y Chile, sobre el eje de la costa del Pacífico y al occidente de la cordillera de Los Andes ${ }^{8}$.

El crecimiento vial carretero se incrementa desde fines del siglo XX, pero con mayor intensidad en el XXI. El predominio de las vías carreteras se fortalece en las políticas de integración sudamericana que implican, cada vez más, compromisos del Estado boliviano para la evolución articulada de las diferentes vías de transporte, aunque se privilegia el carretero. Sus antecedentes se pueden rastrear ya en las décadas de 1970, cuando Bolivia participa del Instituto para la Integración de América Latina y el Caribe (INTAL), dependiente del BID y se incluye en la "Red Fundamental de Transporte en el Cono Sur” cuya versión final se concreta en 1980 (OEA, 1985:15). Desde entonces, también se produce una evolución de la institucionalidad boliviana para desarrollar las coordinaciones que garanticen su funcionamiento eficiente, aunque la ejecución de tales desafíos tropieza con muchas dificultades en la amplitud y diversidad del territorio boliviano. Cabe aclarar que en el caso boliviano las carreteras y su gestión se privatizan parcialmente. Por ejemplo, se da en concesión el cobro de peajes (De Marchi, 2014:128), pero su mantenimiento se guarda bajo la titularidad estatal.
8. El ambicioso proyecto implica la conexión de Bolivia con Puno en Perú, pasando por La Paz, Oruro y Potosí, articulando Tarija, para salir luego por Bermejo. Así, los caminos mencionados en ambas iniciativas, cuentan con una priorización que les permite tener mayor jerarquía respecto a otros tramos que se mantiene hasta la actualidad, rasgo proporcionado por su intención de comunicación continental. 


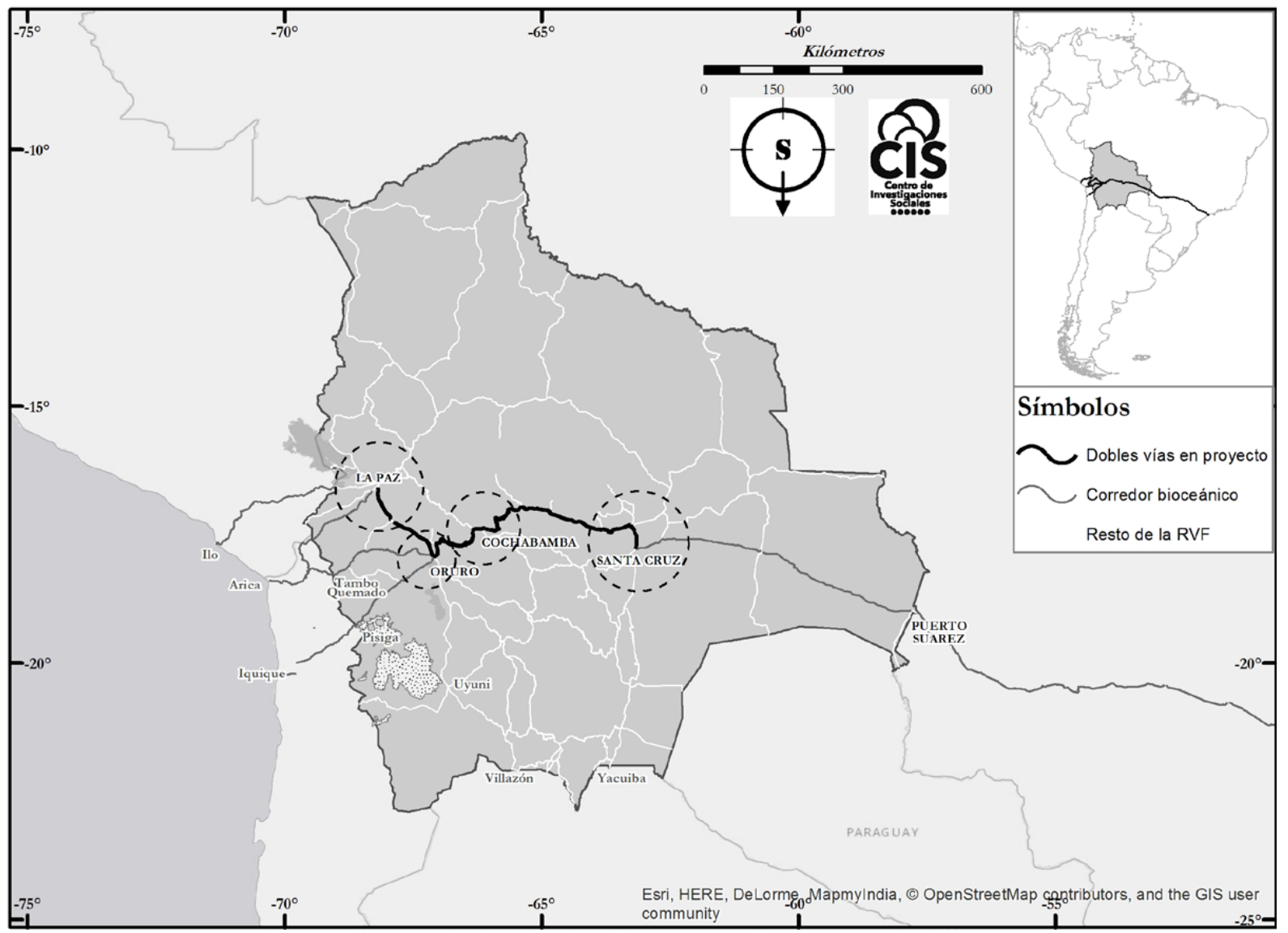

Esa lógica de estructuración continental de las carreteras se mantiene hasta hoy, fomentada por compromisos multilaterales sudamericanos, como la Integración de la Infraestructura Regional Suramericana (IIRSA), que desde el 2009 se articula en el Consejo Suramericano de Infraestructura y Planeamiento (COSIPLAN) ${ }^{9}$. Así, aunque el gobierno de Evo Morales centraliza desde 2006 la gestión de las carreteras (a través de la Administradora Boliviana de Carreteras (ABC)), no cuestiona su articulación a la dinámica de integración regional heredada del periodo anterior. De hecho, uno de los criterios que se mantiene para jerarquización de ciertos tramos carreteros como parte de la Red Vial Fundamental (RVF) se relaciona con su carácter de corredor regional, que comunica pasos de frontera clave y nodos de países vecinos ${ }^{10}$. Así, si en 1994 la planificación estatal busca "un país de integración regional, de contactos entre los países vecinos y nexo entre las cuencas del Pacífico y del Atlántico" (MDSyMA, 1994:61), la “agenda patriótica 2025” publicada en 2014 mantiene metas similares, tanto en su pilar 2, donde alude a "la integración regional con los países vecinos", como en el pilar 10, referido a la "Integración complementaria de los pueblos con soberanía" (Estado Plurinacional de Bolivia, 2014).

Cabe subrayar que son rutas cuyo trazo casi se sobrepone a las antiguas conexiones internacionales ferroviarias (comparar Figuras 1 y 2). Además, la materialidad de las carreteras evidencia que esos tramos se consolidan con superficie asfaltada recién en el siglo XXI. Si bien el contexto internacional favorable alienta la vinculación regional por lo menos desde 1950, la construcción efectiva de los trazos bolivianos tarda en consolidarse $^{11}$.

En ese marco, la conclusión de la carretera bioceánica en 2013 no es un hecho menor, sino el resultado de más de 60 años de desarrollo carretero y de esfuerzo estatal para favorecerlo. Se constituye en la materialización de la apuesta boliviana de ser un país de
Figura 2. Mapa de carreteras de la Red Vial Fundamental. Fuente: Elaboración propia.

9. Para comprender el desarrollo de esos acuerdos es central revisar el apoyo y la relevancia de actores y financiadores externos. Estos responden cada vez menos a la influencia de los Estados Unidos de América y más bien se articulan a los compromisos regionales por producir una movilidad ágil (De Marchi, 2014: 130). Al respecto, se sugiere consultar la página web: http://www.iirsa. org/Page/Detail?menultemld=121

10. La idea oficial de (RVF), con una lógica exclusivamente carretera, se establece en 1998 con tres niveles camineros que se mantienen hasta la actualidad: la red fundamental (cuya codificación corresponde a la letra "F"), la red complementaria o departamental (“D”) y la red vecinal o municipal ("M").

11. Por ejemplo los tramos La PazTambo Quemado y Santa Cruz-Puerto Suárez. Ambos son paralelos y casi superpuestos a las vías existentes del tren. La primera parte es inaugurada en 1996 conectando La Paz con el puerto de Arica y la segunda en 2013 vinculando Santa Cruz con el Brasil. Entonces, se evidencia que recién el 2013 se constituye efectivamente un corredor que atraviesa Bolivia de Este a Oeste con el potencial de unir el Atlántico con el Pacífico. 
contactos. En Bolivia, las carreteras de la denominada Red Vial Fundamental buscan priorizar y facilitar el transporte entre las ciudades principales del país y comunicarse con los países vecinos. Según los datos del Viceministerio de Inversión Pública y Financiamiento Externo (VIPFE), la inversión anual presupuestada y ejecutada para el desarrollo de vías transporte se acerca a un tercio de todo el Presupuesto General del Estado (PGE) desde el año 2000. Se trata de una inversión estatal prioritaria para el gobierno central y su gestión del territorio. Por eso, la mejora del sistema de carreteras es importante en el último decenio. De hecho, el diseño de "dobles vías", capaces de contener un mayor y más acelerado flujo de vehículos, es una de las políticas fuertes de la $\mathrm{ABC}$ en la actualidad. Son 16 los proyectos de construcción de ese tipo en el país, en rutas del denominado eje troncal con miras a conectar los puertos del Atlántico y del Pacífico (Figura 2).

Esos proyectos de doble vía se proponen sobre trazos carreteros que tienen décadas de antigüedad y cuya vialidad se busca mejorar. Son carreteras que desde fines del siglo XX relacionan poblaciones y producen nuevos nodos de distribución del tráfico regional y local. Así, en los últimos años, se evidencia el crecimiento y la transformación de muchas de las localidades articuladas por su trazo. Las oportunidades de accesibilidad que el flujo de transporte genera, así como la economía de servicios que implica, favorece una concentración poblacional importante y un crecimiento urbano acelerado en algunos casos. Es por tal motivo que la concreción del proyecto carretero bioceánico supone todo tipo de expectativas ${ }^{12}$. Sin embargo, a poco tiempo de inaugurada la carretera Bioceánica, donde se localizan parte de las dobles vías, el Estado boliviano plantea la construcción del Corredor Ferroviario Bioceánico de Integración (CFBI). El proyecto es perfilado como "el canal de Panamá del siglo XXI" (MOPSV, 2016) y propone a Bolivia como un centro logístico de importancia continental, que vincule el puerto Atlántico de Santos en Brasil, con el de Matarani o Ilo-Perú en el Pacífico.

Dos cuestiones sobresalen del planteamiento. La primera es la elección del puerto de salida, que privilegia a Perú y no a Chile como conexión en el Pacífico. Eso se explica por los conflictos históricos de Bolivia de acceso a puertos chilenos, cuya lectura oficial se registra en el pilar 13 de la "agenda patriótica 2025" (Estado Plurinacional de Bolivia, 2014). Asumimos que la decisión busca contrarrestar la dependencia respecto a los puertos chilenos que Bolivia mantiene a lo largo de más de una centuria y que tiene a los ferrocarriles primero y a las carreteras después, como principales protagonistas (Figura 4). La segunda cuestión sobresaliente es el discurso gubernamental relacionado con la percepción del rol de Bolivia en el subcontinente; el gobierno central boliviano lidera política y técnicamente el proyecto, lo difunde a nivel internacional más allá de los países vecinos involucrados, en eventos como la Reunión de Alto Nivel Sobre Transporte Sostenible de Países en Desarrollo sin Litoral y otros escenarios multilaterales. Así, organiza encuentros periódicos de grupos de trabajo para coordinar actividades con Paraguay, Brasil y Perú en busca de consolidar el proyecto, en el que ya ha ejecutado más de 6 millones de \$US por concepto de estudios estratégicos. Además, Bolivia ya invierte 317 millones de \$US en la construcción del tramo ferroviario Montero-Bulo Bulo, fondos provenientes del Tesoro General de la Nación (VMT, 2015). Esos elementos permiten sugerir que Bolivia busca ser el actor regional de mayor peso en ese proyecto, en una muestra directa de sus intereses por generar una mayor gravitación económica y política.

Ahora bien, recordemos que tanto la intención de consolidar un corredor bioceánico, como la percepción boliviana acerca de su ubicación estratégica, aparecen esporádica pero constantemente en la historia. De hecho, la primera intención relacionada con la idea de un corredor ferroviario se registra tan tempranamente como 1928, para construir un ferrocarril interoceánico precisamente entre los puertos de Santos (Brasil) y Arica (Chile) (Fifer, 1966:369). Desde entonces, se convierte en una proyección
12. Hace menos de cinco años este hecho es registrado por el diario La Razón, en su nota del 21 de marzo del 2013: “Los últimos 35 kilómetros que faltaban en territorio boliviano para unir el Atlántico y el Pacífico a través de una ruta interoceánica que conecta puertos y ciudades de Brasil, Bolivia, Perú y Chile, ya están concluidos y abren nuevos horizontes al comercio [...] La carretera interoceánica "nos permite ser un eje integrador en todas las direcciones [...] y planificar un centro de distribución de carga como si fuera un puerto hacia los países vecinos", señaló Luis Alberto Castro, jefe de Obras Públicas de la gobernación de Santa Cruz". 


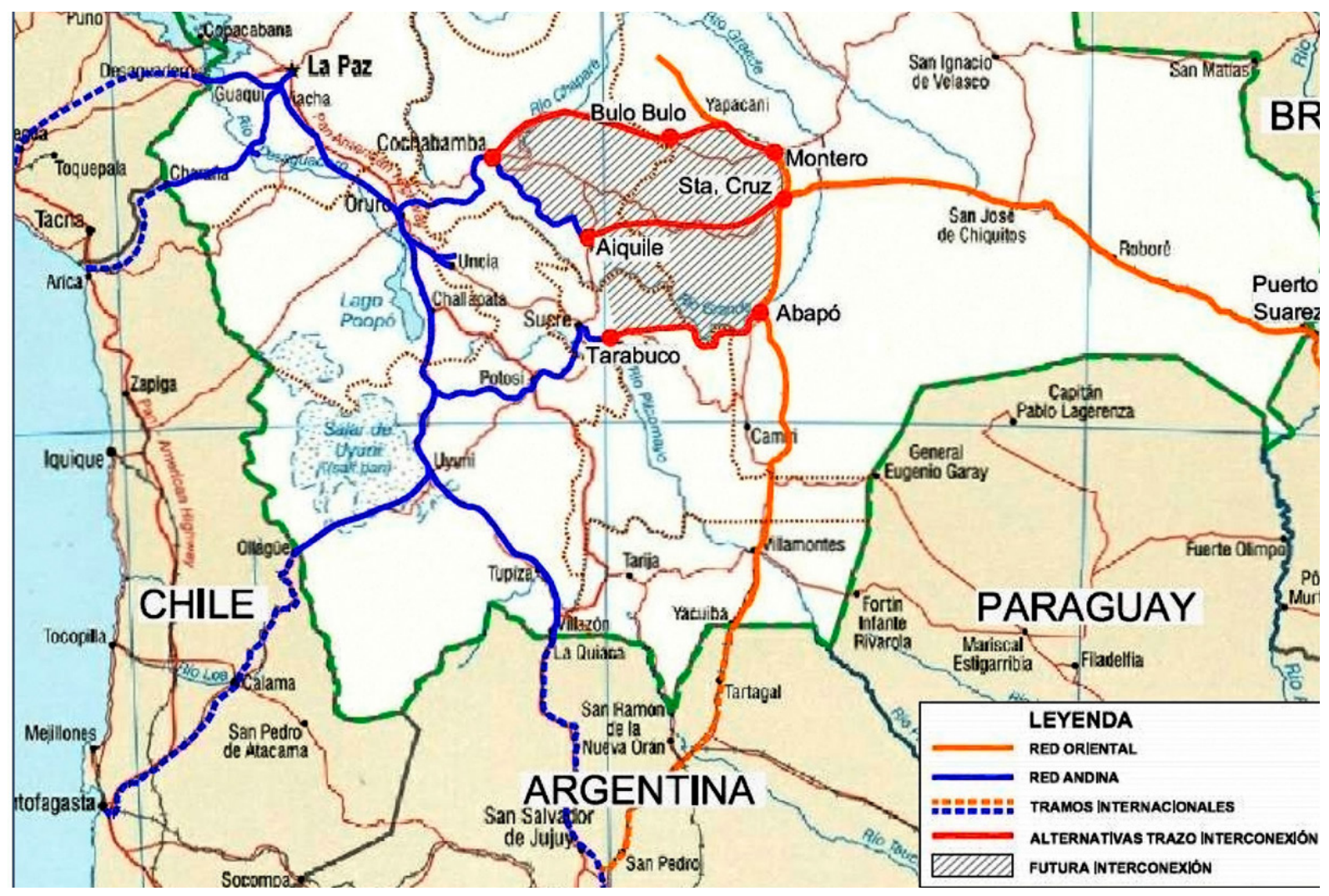

reiterativa a lo largo del siglo XX y se articula al discurso de Bolivia como un país de contactos. En ese sentido, se propone la Ferrovía Transcontinental como una: “... fantasía patriótica” (Córdova, 2015) en la intención de retomar el proyecto de atravesar el país con vías férreas y de unir las redes Oriental y Occidental, que hasta hoy se encuentran separadas.

Sobre este último apunte de inconexión uno de los estudios realizados para el CFBI indica:

La falta de interconexión actual en territorio boliviano impide el tráfico ferroviario continuo en todo el corredor, deficiencia que no puede ser resuelta mediante el transporte carretero por su limitada capacidad de carga y las elevadas tarifas como para absorber la demanda de carga que se proyecta en el futuro, aspecto que convierte a Bolivia en obstáculo para el transporte y el comercio internacional (VMT, 2013:1).

Para solucionar esa falta de articulación ferroviaria se proponen tres alternativas ${ }^{13}$, todas ellas sobre la base de antiguos proyectos (ver Figura 3). El trazo que recorre por el Norte corresponde a la ruta elegida, debido a que "se ha tenido en cuenta el proyecto de YPFB "Planta Amoniaco - Urea" localizado en el Departamento de Cochabamba (provincia Carrasco) [en] Bulo Bulo, que demanda el transporte ferroviario de la urea a través del "Corredor Ferroviario Bioceánico Central" (VMT, 2013:5).

El CFBI se perfila como el proyecto de infraestructura vial más importante de Bolivia en la actualidad, aunque su relación con el corredor carretero concluido el 2013 no es clara. En efecto, ambos ejes están casi superpuestos, son construidos bajo el mismo discurso de integración continental y movilizan similares expectativas de mejoras económicas y comerciales en la región. Lo que no se evidencia explícitamente en el discurso gubernamental es la gestión de la competencia que se prevé generar (o no)
Figura 3. Mapa de alternativas de trazo para unir las redes Oriental y Occidental. Fuente: VMT, 2013:3.

13. Trazo Norte: $(403,5 \mathrm{~km}$ de longitud, lo que convierten al trazo Norte en la alternativa de mayor longitud de las tres); Trazo Centro: $(348,5 \mathrm{~km})$; Trazo Sur: $(318$ $\mathrm{km}$ de longitud. Es el más corto de las tres alternativas estudiadas) 
entre ambos medios de transporte. La construcción del CFBC es particularmente discutible a la luz del mejoramiento y ampliación de las carreteras del eje central La Paz-Oruro-Cochabamba-Santa Cruz que demandan una inversión anunciada, en distintos medios de comunicación, de 1.850 millones de \$UD. Cabe recalcar que el modelo de carretera de doble vía tiene un propósito similar que el CFBC: agilizar la circulación e incrementar el movimiento de carga en volumen y peso, uniendo las costas del Pacífico y el Atlántico.

Ahora bien, la superposición física de ambos corredores en construcción y la semejanza en sus objetivos no pasa desapercibida en los estudios estratégicos del CFBI. A partir de lo señalado en los informes oficiales, podemos afirmar que las inversiones en las vías para ambos medios de transporte están dirigidas a facilitar la circulación de carga a través de los corredores, aunque la movilización de pasajeros se propone como una prioridad para el caso carretero. Así, cuando se realiza la valoración de las posibilidades del servicio de los trenes en proyección, se menciona:

El tráfico de pasajeros es marginal y no rentable, requiere un estudio más profundo en especial en zonas metropolitanas. Los estándares de calidad que se requieren para hacerlo competitivo difieren mucho de los actuales y requieren fuertes inversiones. [...] Los costos comparados entre modos se aprecian un poco optimistas a favor del ferrocarril. [...] No hay estudios de demanda rigurosos por tramos hasta el momento por lo que el que se está haciendo en la actualidad se considera fundamental. [...] No obstante, es importante trabajar en el transporte carretero que es informal en la actualidad. Esto es clave si se quiere potenciar el modo tren pero hay que actuar en gran medida cuando este sea ya una alternativa adecuada. Las políticas de fiscalidad también son muy importantes, el diésel está subvencionado en ambos modos (VMT, 2013:180).

Las sugerencias del proyecto muestran que el gobierno central boliviano intenta establecer un mejor control sobre el tráfico de cargamentos en el CFBI, o al menos uno mucho mayor que el ejercido por su débil presencia en las carreteras.

Es relevante señalar que la decisión del desarrollo de los proyectos carreteros de doble vía se asocia directamente a la demanda de los actores del transporte automotor pesado, cuyo peso político y económico es significativo en el contexto social boliviano. De hecho, su posicionamiento les permite una movilización de cargas que reproduce un dominio casi monopólico sobre las rutas de la RVF (Carlo, 2013; Chirino et al., 2013) ${ }^{14}$, situación que se replica en el transporte de pasajeros y urbano (Alemán, 2009; Justiniano et al., 2014). Las cámaras de transporte y sus afiliados (empresas, asociaciones y sindicatos) controlan ciertas rutas y tipos de cargas sobre la red fundamental. Por eso, en base a nuestras observaciones y sistematización de información, sugerimos que el CFBI está dirigido a invertir la dependencia boliviana de los puertos chilenos, en el marco del discurso de "país de contactos"; pero también busca facilitar el control del Estado central sobre la transitabilidad expedita de cargas por medio de una vía más fácil de controlar: el tren.

Un elemento que permite profundizar lo expuesto se relaciona con el uso del bloqueo de caminos como medida de presión en caso de conflicto social, que es muy común en la dinámica política y social boliviana. De hecho, al inicio del siglo XXI, esa estrategia de presión y de ejercicio de poder: la interrupción del flujo continental sobre la vía, principalmente sobre el corredor carretero bioceánico, es determinante para el giro político boliviano y el ascenso a la presidencia de Evo Morales, con apoyo de los sindicatos cocaleros de El Chapare. En vista del valor estratégico y discursivo de la ruta bioceánica para Bolivia, es lógico que el gobierno busque alternativas de movilidad para lograr mayor control sobre la vía y sobre el tráfico, evitando su interrupción y su
14. Las referencias mencionadas ratifican la dinámica del transporte, al igual que los trabajos de campo desarrollados por el equipo CIS en torno a las rutas de Oruro, Camiri y Riberalta (datos principalmente cualitativos cuyo procesamiento y publicación está en curso). 
control disperso. En ese sentido, un corredor multimodal -férreo y carretero- es más difícil de bloquear en caso de convulsión social y permite reducir la monopolización del flujo por intereses corporativos externos o paralelos al Estado.

\section{Nodos y dinámica contemporánea}

Las condiciones materiales actuales para concretar el flujo Atlántico-Pacífico han reactivado la narrativa del "país de contactos". El longevo discurso se enlaza hoy con iniciativas técnicas de circulación a través de Bolivia, que cuentan con el apoyo político suficiente para su realización. Es un proyecto que busca articular más eficientemente el espacio boliviano al flujo global, dentro del sistema-mundo (Wallerstein, 2006) y su dinámica comercial internacional. De ahí que el transporte y la movilización de cargas mantengan el protagonismo en los proyectos territoriales estatales, así como el planteamiento de facilitar el paso por Bolivia desde las costas y los puertos de ambos océanos a otros países. Los ejemplos que concretan esa intención son el CFBI y las dobles vías del corredor bioceánico, planteados como proyectos más concurrentes que complementarios. Se trata de facilitar la articulación a los demás países, profundizando la idea de ganar un peso estratégico en la movilización de productos a escala global.

Sin embargo, un elemento transversal a la hora de pensar el territorio, es la forma en que las dos métricas (Mezoued, 2015), la automotriz y la ferroviaria, afectan de forma distinta la composición del espacio y la articulación de los actores sociales interesados en la movilidad. Bajo esa perspectiva, y complejizando la escala de análisis, este apartado pretende explorar los cambios sufridos en algunos nodos por donde pasan las vías de transporte antes mostradas, entre los cuales circulan las personas, tejiendo relaciones económicas y sociales. Por una parte, es necesario tomar en cuenta las posibilidades de gestión del sistema ferroviario y la forma en que el tren recorre y recompone el espacio, que permiten el desarrollo de un sistema más controlado centralmente. En contraste, el sistema carretero boliviano muestra una articulación de mayor reticularidad y fricción con el territorio, pero de bajo control del Estado, ya que su administración es prácticamente delegada a las asociaciones, sindicatos, cooperativas y empresas de transporte. De hecho, la historia de ambos modos de transporte y la forma en que dinamizan el territorio que atraviesan en los periodos revisados, es clave para esa discusión, porque da cuenta de la forma en que el territorio modifica su estructuración a partir de un tipo de camino ${ }^{15}$.

A fin de abordar esta reflexión, proponemos analizar con mayor detenimiento una parte del eje bioceánico, que corresponde a los trazos carreteros y ferroviarios que comunican los nodos de los departamentos de Oruro y La Paz con las costas del Pacífico. Como precedente, es relevante apuntar la densidad histórica de los caminos de la zona en la que nos enfocamos. Oruro es una ciudad colonial, fundada en 1606, que junto a Potosí articula la dinámica vial de la minería de la plata (López, 2016:62). Cabe subrayar que, el sistema caminero de la zona es de origen prehispánico, pero luego es adaptado a la lógica de la colonización española y a sus intereses, privilegiando algunos destinos y rutas particulares. Así, en la colonia se establece al puerto de Arica como una de las salidas de exportación del mineral y luego, ya en la etapa republicana, serán los puertos de Cobija y Antofagasta los oficiales (ibíd.). De esta forma los lazos del altiplano orureño con el Pacífico son muy antiguos y -pese a los drásticos cambios históricos- las tendencias de vinculación permanecen en el tiempo de manera intensa. Sin embargo, cuando revisamos el tipo de vía que concreta esas vinculaciones y los nodos asociados a ella, se evidencian las diferencias que éstas producen. La Figura 4 y el Cuadro 1 muestran los nodos que evaluamos y su relación con las vías.
15. Por ejemplo el estudio sobre ventajas comparativas y competitivas del comercio regional orureño del PIEB revela que el transporte por carretera carga un $51,15 \%$ el valor de las exportaciones y el $66,53 \%$ de las importaciones, mientras que los ferrocarriles sólo transportan el $14,44 \%$ de las exportaciones y el 11,03\% de las importaciones (Sanjines, 2002:123). 


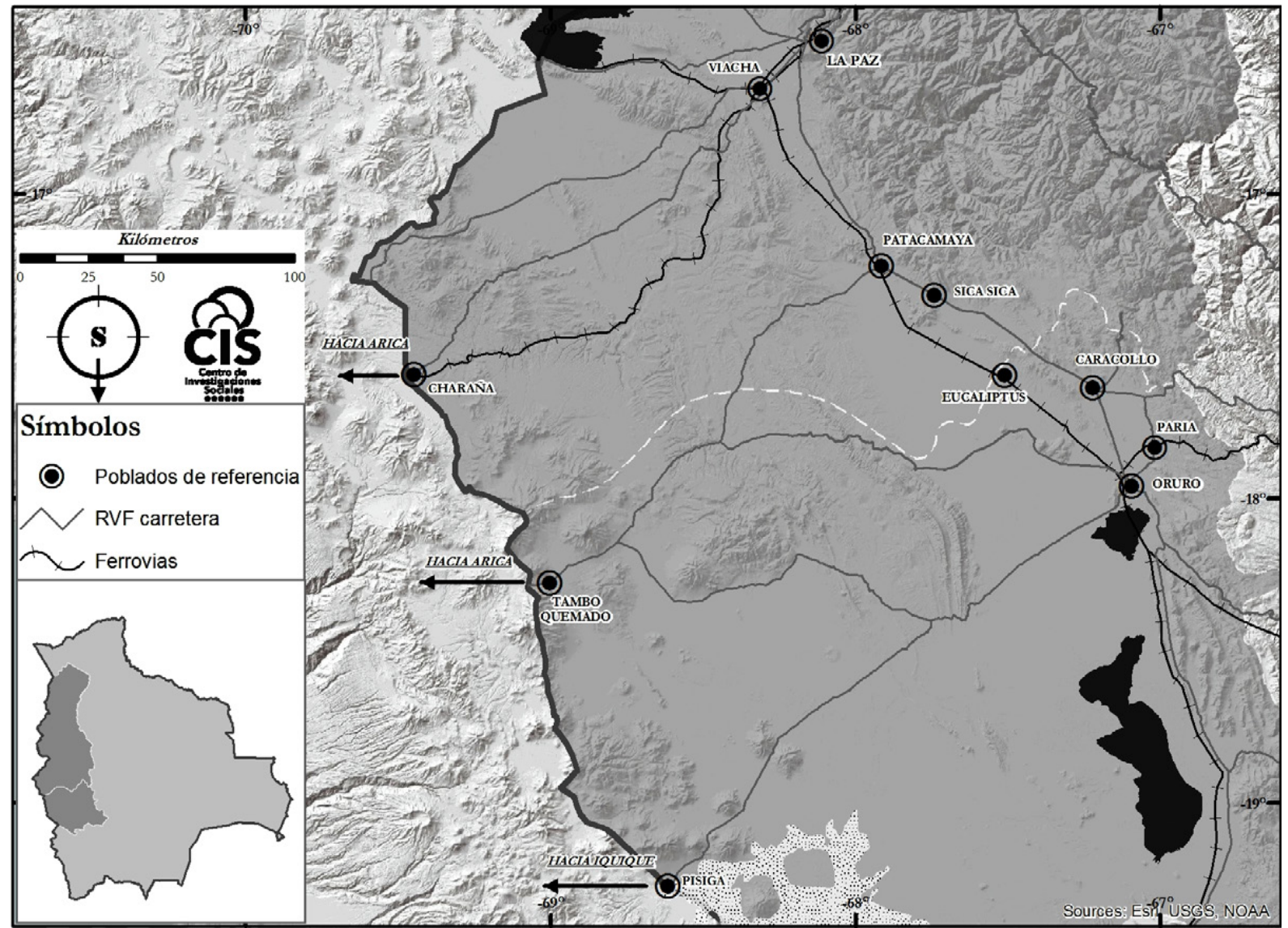

Cuadro 1. Comparativa de centros poblados y asociación a vías de transporte carretero y ferroviario. Fuente: Elaboración propia.

\begin{tabular}{|l|c|c|}
\hline & \multicolumn{2}{|c|}{ Asociación con una vía y modo de transporte } \\
\hline Nodo Analizado & Ferroviario & Carretero \\
\hline Viacha & $\mathrm{X}$ & $\mathrm{X}$ \\
\hline Charaña & $\mathrm{X}$ & $\mathrm{X}$ \\
\hline Oruro & $\mathrm{X}$ & $\mathrm{X}$ \\
\hline Patacamaya & $\mathrm{X}$ & \\
\hline Eucaliptus & $\mathrm{X}$ & $\mathrm{X}$ \\
\hline Paria & $\mathrm{X}$ & $\mathrm{X}$ \\
\hline Caracollo & & $\mathrm{X}$ \\
\hline Sica Sica & & $\mathrm{X}$ \\
\hline Tambo Quemado & & \\
\hline Pisiga & & \\
\hline
\end{tabular}

Como muestra la Figura 4, los tramos ferrocarrileros están marcados por diferentes características. Por ejemplo, aunque históricamente el tramo Viacha-Charaña es una vía de intenso movimiento durante inicios del siglo XX, hoy sólo queda una circulación reducida de pasajeros en buses-carriles. Así, cuando ese modo de transporte pierde importancia y se asienta el tráfico carretero como dominante en la segunda mitad del siglo XX, la estación de Viacha entra en decadencia, aunque su relevancia como centro poblado se incrementa gracias a su proximidad respecto a la conurbación de la ciudad de La Paz y a su rol como nodo articulador con Chile y Perú. Otras estaciones en la ferrovía que siguen la misma dinámica decadente son Paria y Eucaliptus. El primero es
Figura 4. Mapa de trazos carreteros y ferroviarios de La Paz y Oruro al Pacífico. Fuente: Elaboración propia. 
una estación clave antes de Oruro y en el inicio del descenso hacia el valle de Cochabamba, el segundo ocupa una posición intermedia entre Patacamaya y Oruro que la convierte en una estación preferida para la salida de minerales de la provincia Inquisivi. Ambas poblaciones, exclusivamente ferroviarias, quedan en una especie de periferia con la reorganización territorial que generan las nuevas carreteras. Esa situación las deja fuera de cualquier circuito de circulación y crecimiento principal. En el mapa, el paso de frontera de ese tramo de tren supone el desarrollo de una marca (Benedetti, 2015) específica: Charaña, nodo que con la decadencia férrea también pierde relevancia.

Aunque se podría pensar que esta suerte de contracción sería la constante para todas las centralidades que fueron estaciones del tren, el caso de Patacamaya muestra todo lo contrario. La posición geográfica de ese asentamiento y su doble vinculación (ferroviaria y carretera), facilita un crecimiento poblacional exponencial, que luego constituye un nodo articulador entre ciudades capitales ( $\mathrm{La}$ Paz y Oruro) ${ }^{16}$ y Tambo Quemado, en la frontera con Chile (ver Cuadro 2). El crecimiento poblacional urbano que presenta Patacamaya parece no deberse únicamente a la presencia de la carretera, sino a su rol articulador de distintas vías y medios de transporte.. De esta forma la ubicación geográfica y su vínculo con un paso de frontera aparecen como factores determinantes. En una escala de mayor proximidad, el ejemplo de Patacamaya pone en evidencia cómo su dinámica local está fuertemente afectada por el flujo que supone cada tipo de métrica de transporte en diferentes momentos. De hecho, la morfología y sus principales actividades urbanas cambian su ubicación a lo largo del siglo XX, primero en función a la estación del tren y luego en torno a la carretera.

Cuadro 2. Datos de población según censos nacionales. Fuente: elaboración propia en base a datos del INE.

\begin{tabular}{|l|c|c|c|c|c|c|}
\hline Nodo & $\mathbf{1 9 0 0}$ & $\mathbf{1 9 5 0}$ & $\mathbf{1 9 7 6}$ & $\mathbf{1 9 9 2}$ & $\mathbf{2 0 0 1}$ & $\mathbf{2 0 1 2}$ \\
\hline Patacamaya & sin registro & 1.278 & 2.467 & 5.950 & 8.414 & 11.249 \\
\hline Sica Sica & 1.795 & 1.486 & 1.590 & 1.618 & 3.881 & 3.137 \\
\hline
\end{tabular}

En contraste, como observamos en la Cuadro 2, la población de Sica Sica carece de todos estos atributos de articulación (como la mayor parte de los centros poblados del altiplano), razón por la que su crecimiento poblacional es mucho menos acelerado e incluso tiende al decrecimiento en los períodos 1900-1950 y 2001-2012. La contracción poblacional de 1950, posiblemente, se vincula a que el trazo de la ferrovía deja de lado ese asentamiento, al priorizar un trazado con menos curvas y más económico, que crea nuevas centralidades. De ahí que, en el caso de Sica Sica, vemos una suerte de estancamiento en el crecimiento poblacional.

El diseño de las ferrovías occidentales prioriza la exportación de minerales (primero plata y luego estaño) y la importación de productos, pero también se justifica con la idea de articular y "beneficiar" con mayor accesibilidad a diferentes partes del territorio que atraviesa. Sin embargo, su flexibilidad de diseño es menor que el de una carretera. Observando la Figura 4, el mapa muestra que, en esta zona, Bolivia tiene hoy 3 salidas carreteras hacia el Pacífico y sólo una ferroviaria. De hecho, sólo las salidas carreteras son las que funcionan actualmente como ya hemos comentado. Esta característica ha generado, lógicamente, nuevas marcas en la frontera con Chile, primero al relativizar el paso de Charaña y al favorecer la dinámica de Tambo Quemado y Pisiga. Todos estos nodos están articulados por la RVF con la característica de ser parte del corredor bioceánico. Claramente existen mayores posibilidades de alcanzar la costa por medio de vías carreteras.

Las nuevas formas de movilidad instaladas con la construcción de la doble vía, bajo la concepción de mayor aceleración, suponen modificaciones en la red vial descrita y en
16. Otro efecto de la red vial automovilística se muestra en el cruce de caminos entre las ciudades capitales de La Paz, Oruro y Cochabamba, en Caracollo. Se trata de un asentamiento que durante el ciclo del tren queda fuera de su trazo, pero que hoy en día es fundamental, dado que funciona como distribuidor y punto de descanso para los buses de pasajeros que circulan entre esas ciudades. 
la configuración de los lugares. Por ejemplo, la noción de circunvalaciones, que evitan los centros poblados y conducen el tráfico pesado lejos de las manchas urbanas, implica que la dinámica económica instalada en torno a la oferta de servicios para el transporte se vea afectada en los nodos intermedios. Observamos los casos específicos de Patacamaya y Caracollo que luego de ser referentes carreteros de servicios durante décadas, se ven afectados notoria y rápidamente por las circunvalaciones del diseño de doble vía. En términos generales, la necesidad de lugares de pausa se reduce con el incremento de la velocidad, afectando las posibilidades de fricción con el territorio atravesado y generando menos contacto con los nodos, cuya economía hasta ahora está volcada a los servicios para ese flujo automovilístico ${ }^{17}$.

Estos elementos nos llevan a cuestionar cómo podría afectar el tren bioceánico al sistema descrito. Posiblemente, la vocación casi exclusiva hacia el transporte de cargas y su concepción como túnel de mercancías permiten sostener que su efecto sea diferenciado por la escala. Si bien el diseño carretero es más flexible que el ferroviario y tiene la capacidad de producir más fricción con los territorios que articula, es evidente que el nuevo diseño de dobles vías en Bolivia está destinado a reducir ese contacto y cambiar la escala de interacción territorial, de una local a otra más bien regional e internacional. En ese mismo sentido, la apuesta del CFBI no es la de un camino que facilite la accesibilidad y la integración de las poblaciones, sino de las cargas y de su intercambio entre países, sin reparar en producir mayores efectos en las escalas locales. Los documentos estratégicos del CFBI no contemplan, por ejemplo, la reactivación de pequeñas estaciones como Paria o Eucaliptus, pues la capacidad de funcionamiento y control sobrepasan ampliamente esa escala territorial. Por eso, sostenemos que el CFBI tiene el potencial de afectar nodos carreteros, como el de Pisiga que adquiere mayor importancia en años recientes por la reciente inauguración (2017) de la carretera asfaltada que conduce hacia Iquique y que es hoy, la vía principal de importación y exportación para Bolivia con las costas del Pacífico por Chile. Así, posiblemente sean las marcas fronterizas las afectadas de forma evidente, pero no los entornos locales cuya dinámica contemporánea se concentra en los flujos internacionales.

\section{Comentarios finales}

Lo mostrado permite subrayar la progresiva concreción del discurso del país de los contactos: incompleta en la etapa férrea y más avanzada en el periodo carretero. Pero también, en el último apartado, se evidencia cómo esas decisiones estatales sobre la infraestructura vial, que buscan facilitar la travesía de los flujos sobre el territorio boliviano, afectan y modifican los nodos que lo componen. Tomando en cuenta que existe una decisión gubernamental de continuar con la profundización de esa concepción en ambos modos de transporte, cabe preguntar ¿podrá el CFBI, al menos, equilibrar la importancia de las conexiones viales carreteras hacia Chile?, ¿qué implicaciones tiene la decidida inversión en carreteras hacia el Pacífico en términos de competencia para el CFBI?, ¿Cómo afectará la disminución del flujo carretero de cargas en la estructuración territorial boliviana? Se trata de preguntas a debatir en el contexto de intervención sobre la movilidad a gran escala que promueve el Estado.

Existe una tendencia histórica de proyectar una integración continental en la que Bolivia se enuncia como protagonista central. Así, parece estar superada la lógica de los transportes exclusivamente binacionales y transfronterizos que caracterizaron el inicio del siglo XX. Los intentos por cubrir esa necesidad de conexión continental se observan en los diferentes planes estatales, aunque recién logran concretarse en el siglo XXI. Así queda en evidencia que la narración del "país de contactos" atraviesa el siglo XX (Perrier-Bruslé, 2015:121) y continúa como una retórica vigente en la actualidad.
17. Al respecto, es significativo recuperar una nota del periódico Página Siete del año 2015: “Ana María Calderón (48 años) tiene un puesto de desayuno y almuerzo a escasos 100 metros de la entrada a esta localidad. Sus clientes eran pasajeros que iban de La Paz a Oruro y que también hacían el viaje inverso. Los 50 platos de almuerzo que solía preparar se redujeron a 25; y los 80 vasos de café y api se transformaron en sólo 30 por día. "Por circunstancias de la carretera nos ha afectado mucho; es silencio, ya no hay pasajeros y nos afecta porque nosotros ganamos al día nomás", comenta”. 
Complementando esa perspectiva de fines de siglo, Daniel Agramont destaca una visión más amplia que se mantiene y profundiza en el siglo XXI: “... la nueva política exterior boliviana [...] no está limitada al intercambio de mercancías, sino que abarca también el intercambio cultural, social científico, político y tecnológico, basado en la complementación de las disponibilidades y capacidades de cada pueblo" (Gobierno Nacional de Bolivia, 2006:17-18)" (en Agramont, 2010:26). Sobre el tema, Letitia Perrier-Bruslé sugiere que: "esta supuesta centralidad es la única forma para que Bolivia asiente su presencia en la escena continental, sabiendo que el país carece de toda posibilidad para construir un liderazgo verdadero" (Perrier-Bruslé, 2015:119). Pese a esos enunciados oficiales y los análisis evocados, no existe mayor discusión de cómo este discurso y la infraestructura que produce permiten efectivizar la accesibilidad y el intercambio en las poblaciones de los nodos afectados por las vías.

Aun así, es evidente que la percepción boliviana sobre el territorio está cambiando. Las propuestas técnicas tienen expresiones espaciales que concretan el discurso boliviano de "país de contactos" y al mismo tiempo le dan fuerza. Los financiamientos desde el Estado y desde los créditos que viabiliza apuntan al avance del sistema carretero boliviano y profundizan esas concepciones, pese a la aparente carencia de una planificación integrada en términos de intermodalidad. La forma en cómo la cuestión ferroviaria se conecta o compite con la carretera no es evidente. Sin embargo, la posibilidad de fortificar una lógica ferroviaria estatal parece coherente con la concepción política del actual gobierno boliviano de fortalecer un control central. Reducir la dependencia de los puertos chilenos es parte de los argumentos en juego, pero a él se suman otros, también política y económicamente relevantes. Así, reducir la centralidad del transporte de cargas por automóvil (privado y corporativo), evitar los bloqueos de ruta e incrementar el control estatal del tráfico de mercancías son decisiones importantes que justifican la retoma del transporte férreo. Posiblemente se trata de un intento, progresivo y estratégico, de reposicionar al Estado como actor de la movilidad boliviana.

El artículo da cuenta de algunos avances de investigación de un estudio más amplio, que desarrolla el Centro de Investigaciones Sociales (CIS) sobre la integración boliviana en la historia republicana y plurinacional. El objetivo general de la investigación es: "analizar cómo los diferentes medios de transporte ( $y$ sus principales vías de comunicación) participan en la construcción del territorio boliviano entre 1825 y 2015, tomando como referencia 3 estudios de caso claves: Riberalta, Camiri y Oruro". Los datos que se muestran e interpretan en este artículo corresponden principalmente al caso de Oruro. El CIS es una Dirección de la Vicepresidencia del Estado Plurinacional de Bolivia "que tiene el propósito de producir investigaciones en ciencias sociales y humanas que contribuyan al fortalecimiento del Estado boliviano" (ver: http://www.cis.gob.bo). 


\section{Bibliografía}

" AGRAMONT, Daniel (2010) Bolivia en los procesos de integración regional. Desafíos y oportunidades ante las nuevas características del regionalismo. La Paz: Friedrich-Ebert-Stiftung (FES). <http://www.academia.edu/5312830/ Bolivia_frente_a_la_integraci\%C3\%B3n_regional_desafios_y_oportunidades_ frente_a_las_nuevas_caracteristicas_del_regionalismo>

» ALEMÁN, Luis (2009) Empresarios al volante. La producción del servicio de transporte público en la ciudad de la paz - bolivia, el caso del grupo 'Hito 45' del sindicato mixto de transportes 'Litoral'. Revista Transporte y Territorio №1, Universidad de Buenos Aires, pp. 144-170. <http://revistascientificas.filo.uba. ar/index.php/rtt/article/viewFile/225/204>

» ALMARAZ, Sergio (1988) El poder y la caída. El estaño en la historia de Bolivia. La Paz: Los Amigos del libro.

» ARAMAYO, Cesareo (1959) Ferrocarriles bolivianos. Pasado presente futuro. La Paz: Imprenta Nacional.

» BIEBER, León (2016) Pugna por influencia y hegemonía. La rivalidad germanoestadounidense en Bolivia. 1936-1946. Santa Cruz de la Sierra: El País.

»BLANES, José, CALDERÓN, Fernando et al. (2003) Formación y evolución del espacio nacional. Cuaderno del futuro 18. La Paz: PNUD, Plural Editores.

»CARLO, Carol (2013) Migrantes, paisanos y comerciantes. Prácticas sociales y económicas en la Zona Franca de Cobija. La Paz: PIEB.

" CASTRO, Ángel (2013) Santa Cruz. La mayor inversión boliviana (1825-2000). La Paz: CEPAAA.

»CHIRINO, Fabiana; GUTIÉRREZ, Julio y SANDOVAL, Dunia (2013) Redes económicas y sociales del transporte interprovincial en Santa Cruz. La Paz: PIEB.

" CONTRERAS, Manuel (2003) Bolivia, 1900-1930: Minería, ferrocarriles y educación. En E. Cárdenas, J. Ocampo, \& R. Thorp (Edits.). La era de las exportaciones latinoamericanas de fin de del siglo XIX a principios del siglo XX. México D.F., Fondo de Cultura Económica, pp.259-296.

»CORBOZ, André (2001) Le territoire comme palimpseste et autres essais. Francia: Ed. de l'Imprimeur.

» CRIST, R. (1944) Bolivia - Land of contrast. Foreign Affairs, 22(4), pp.297-325.

»CUADROS, Álvaro (1996) Ciudad y Territorio La construcción del espacio nacional. La Paz: Cooperación Holandesa en Bolivia. Asociación de ex becarios en Holanda.

»DALENCE, José (2013) Bosquejo Estadístico de Bolivia. Sucre: ABNB.

» DíEZ, Gabriel (2015) Patacamaya ¿está en camino a convertirse en pueblo fantasma?. Periódico Página Siete, 08 de marzo 2015, s/p.

"DE MARCHI, Bianca (2014) Génesis de un territorio a partir del camino: contexto, pretexto, textura y texto de la Red Vial Fundamental de Bolivia en el departamento de Cochabamba. Tesis de Doctorado, Université Cathiloque de Louvain, Lovaina la Nueva. 
» ESTADO PLURINACIONAL DE BOLIVIA (2014) Agenda patriótica 2025. Representación presidencial agenda patriótica del bicentenario 2025.

» FCA (2007) Memoria anual 2007. La Paz: Empresa Ferroviaria Andina S.A.

» FIFER, Valerie (1966) Bolivia's boundary with Brazil: a century of evolution. The geographical journal, 132(3), pp. 360-372.

» FIFER, Valerie (1967) Bolivia's Pioneer Fringe. Geographical review, 57(1), pp.1-23.

»FO (2012) Memoria anual 2012. Santa Cruz: Ferroviaria Oriental S.A. <http:// www.fo.com.bo/AcercaDeNosotros/Publicaciones/01.\%2oMemoria\%2oAnual/ Memoria\%20-\%20FO\%202012.pdf>

» GARCÍA, Pilar (200o) De la colonización depende el porvenir de la república. Una historia de la colonización en Bolivia, 1825-1935. Anuario del Archivo y Biblioteca Nacionales de Bolivia, pp. 53-106, Sucre.

" GUITERAS, Anna (2012) De los Llanos de Mojos a las Cachuelas del Beni 18421938. Conflictos locales, recursos naturales y participación indígena en la Amazonía boliviana. Cochabamba: Instituto de Misionología - Editorial Itinerarios - ABNB.

" INC (1975) Proyecto Chapare - Propuesta de Estudio para el Desarrollo Integrado. La Paz: Organización de Estados Americanos - Departamento Nacional de Desarrollo Regional - Instituto Nacional de Colonización. <http://docplayer. es/10572319-Proyecto-chapare-propuesta-de-estudio-para-el-desarrollointegrado.html>

» JNP (1961) Planeamiento (Vol. 3-4-5). La Paz: República de Bolivia - Órgano Oficial de la Junta Nacional de Planeamiento.

» JUSTINIANO, Hagler; URZAGASTI, Ernestoy VICTORIA, Blanca(2014)Transporte sin rumbo. El transporte público urbano y los desafíos de la modernización en Santa Cruz de la Sierra. La paz: PIEB

" LEMA, Ana María, ALVARADO, Mario (1998) Pueblos indígenas de la amazonía boliviana. La Paz: TCA. <http://otca.info/portal/admin/_upload/documentos/ indigenasBolivia.pdf>

» LIMPIAS, Víctor Hugo (2009). Vías de integración y desarrollo. Las ferrovías y la carretera que transformaron el oriente boliviano, 1938-1957. Ponencia para ingreso a la Academia Boliviana de la Historia.

» LÓPEZ, Clara (2016) La ruta de la plata de Potosí al Pacífico. Caminos, comercio y caravanas en los siglo XVI y XIX. La Paz: Plural Editores.

» MACHICADO, Flavio (2015) Estrategia socio-económica del desarrollo nacional 1971-1991. (2a). La Paz: UMSA.

» MARSH, Alexander (1928) Nuestros banqueros en Bolivia. Un estudio de la inversión de capital norteamericano en el extranjero. Madrid: M. Aguilar Editor.

» MENDOZA, Jaime (1925) El factor geográfico en la nacionalidad boliviana. Sucre: Imp. Boliviar.

" MEZOUED, Aniss (2015) La mise en récit de l'urbanisme algérois, passé, présent, futur. A la recherche des conditions d'institution de l'espace public comme médiation et comme projet. Cas du tramway d'Alger. Tesis doctoral. Louvain-la-Neuve: Presses Universitaires de Louvain.

» MSSyMA (1994) Plan General de Desarrollo Económico y Social de la República. El cambio para todos. La Paz: República de Bolivia - Ministerio de Desarrollo Sostenible y Medio Ambiente. 
» NAVAS, Teresa (2013) Infraestructuras viarias desde la perspectiva histórica: El caso de la formación de la red de carreteras en la región de Barcelona (17611969). Revista de Transporte y Territorio, Nº . Universidad de Buenos Aires, pp.2644. <http://revistascientificas.filo.uba.ar/index.php/rtt/article/view/292/270>

»OEA. (1985) El Transporte en la Cuenca del Plata. Washintong: Secretaría General de la Organización de los Estados Americanos.

" PACHECO, Víctor (1983) Caminos de penetración al norte del departamento de La Paz. La Paz: Editorial Universo.

» PERRIER-BRUSLÉ, Laetitia (2015) La integración continental sudamericana, inscripción espacial y dispositivo discursivo. Apuntes desde Bolivia, el país de contactos. Journal of Latin American Geography, 4(2), pp.101-129.

» RODRÍGUEZ, Gustavo (2012) ¡Ferrocarril o nada! La lucha por la locomotora en Cochabamba, 1892-1927. Revista Estudios del ISHir, 2(3). https://es.scribd.com/ document/234788411/Rodriguez-Ostria-Ferrocarril-o-Nada-La-Lucha-Por-LaLocomotora-en-Cochabamba-1892-1927

»VILLEGAS, Pablo (2013) Geopolítica de las carreteras y el saqueo de los recursos naturales. Cochabamba: CEDIB.

»WALLERSTEIN, Immanuel (2006) Análisis de Sistemas-Mundo. Una introducción. México: Siglo XXI.

\section{Bianca De Marchi Moyano / biancadmm@yahoo.es}

Licenciada en comunicación social, máster en gestión del patrimonio y desarrollo territorial (Universidad Mayor de San Simón, Bolivia) y doctora en urbanismo (Universidad Católica de Lovaina, Bélgica). Responsable de geografía e historia del Centro de Investigaciones Sociales (CIS, Bolivia). Autora de los artículos: "Actores y temáticas en el debate sobre las carreteras..." y “...Representaciones audiovisuales de la movilidad". Participa en los libros: "Kana nos kosta. La recherche-action territoriale en question" y "Les villes non-occidentales...".

\section{Huascar Ignacio Morales Quintela / huascar.hmq@gmail.com}

Licenciado en geografía con estudios en antropología (Universidad Mayor de San Andrés, Bolivia). Actualmente cursa la maestría en población y desarrollo del postgrado en ciencias del desarrollo (CIDES-UMSA, Bolivia). Ha trabajado con pueblos indígenas de tierras bajas y organizaciones sociales para la gestión territorial y la conservación de áreas protegidas. Se desempeña como investigador en el Centro de Investigaciones Sociales (CIS, Bolivia).

\section{María Cristina Machicado Murillo / machicado.lacris@gmail.com}

Egresada en historia (Universidad Mayor de San Andrés, Bolivia). Investigadora del Centro de Investigaciones Sociales (CIS, Bolivia). Publica principalmente sobre temas de finales del siglo XIX y principios del siglo XX. Gestionó diferentes proyectos de conservación documental con la Fundación Flavio Machicado Viscarra (FFMV). 